\title{
La Razón Irónica en Las Tradiciones Peruanas'
}

\author{
Luis Alberto Arista Montoya \\ Instituto de Investigación de la Escuela de Turismo \\ de la Universidad de San Martín de Porres \\ luisalbertoarista@gmail.com
}

\section{Resumen}

Sí. Es posible realizar una lectura filosófica de las Tradiciones Peruanas de Ricardo Palma (7 febrero de 1833- 6 octubre de 1918). Pues, a través de su narrativa discurre una metafísica de las costumbres de su época que utiliza el método estético de la ironía sociológica, vinculandola con la crítica de la razón cínica desarrollada por algunos filósofos.

Palabras clave: Tradición, filosofía, metafísica, crítica, razón, ironía.

\begin{abstract}
Yes. It is possible to carry out a philosophical reading of the Peruvian Traditions of Ricardo Palma ( $7^{\text {th }}$ February 1833- $6^{\text {th }}$ October 1918). Therefore, throughout his narrative it runs the metaphysics of the customs of his time using the aesthetical method of the sociological irony, linking it with the critique of cynical reason developed by some philosophers.
\end{abstract}

Keywords: Tradition, philosophy, metaphysics, critique, reason, irony.

I Lima, 13 de octubre de 2017. Ponencia sustentada en el Instituto Ricardo Palma con motivo de mi incorporación como Miembro de Número. 
Luis Alberto Arista Montoya, Profesor Universitario de Filosofía y Ciencias Sociales. Labora como Profesor Investigador de la Escuela de Turismo en la Universidad de San Martín de Porres. Premio Nacional de Investigación CONCYTEC-1989, por su trabajo "La socialización de los niños en una cultura de violencia"; Premio OEA en Ensayo por su trabajo "Los niños de familias de clase media y los imperativos sistémicos" (México-2004). Ejerció el cargo de Director del diario Oficial El Peruano (1995-96), y de Director Nacional del Instituto Nacional de Cultura de Perú-INC (1996-99). Autor de: Existencialismo y Marxismo en el Pensamiento de Sartre (1984); Ortega y Gasset, Pensador de la Crisis (1993); J. Habermas: Comunicación, Modernidad y Consenso (2004), etc. 


\section{Introducción}

Mi generación escolar -que inició su educación secundaria en 1960-, gracias al valiosísimo texto del curso de Castellano del autor amazonense Humberto Santillán Arista, tuvo un bifronte encuentro con la imagen y obra de don Ricardo Palma, pues la carátula estaba ilustrada con su rostro de maestro, portando unos anteojos redondos, con un poblado bigote. Posteriormente, con el texto de Literatura Peruana, del mismo autor, conocimos su biografía y leímos algunas de sus Tradiciones en la biblioteca del colegio de Ciencias y Artes San Juan de la Libertad, colegio emblemático de la ciudad de Chachapoyas, capital de la Región Amazonas.

Esa inconfundible iconografía se instaló en el imaginario, en la mentalidad y en la conciencia de los estudiantes peruanos. Luego, ya en la universidad, su obra fue más y mejor conocida durante el curso de Literatura Peruana, con la apoyatura teorética de la célebre obra Literatura Peruana. Derrotero para una Historia Cultural del Perú, de Luis Alberto Sánchez. Este autor nos enseñó que Palma fue un escritor presentista, no pasadista, que portaba una "genial ironía" expresada en sus Tradiciones con "gracia estilística". "El ambiente general de las tradiciones peruanas es siempre pintoresco, y su estilo socarrón. No debe confundirse socarronería con chiste ni sarcasmo. Palma pinta lo que ha leído o escuchado, pero en forma tal que deja entrever su escepticismo, más que acerca de los hechos concretos, sobre su significación y alcance" (1973: Tomo III, p. 957), casi siempre con un manojo de anécdotas graciosas, buscando la sonrisa cómplice del lector, sea por simpatía o escepticismo. iY vaya que lo logró!, con creces.

Luego conocimos la obra Ricardo Palma, el Tradicionista, biografía escrita por su hija Angélica Palma, que nos proporcionó mayores datos antropológicos y académicos, que nos sirvieron para 
conocer su trayectoria vital y argumentativa. Vital porque su élan y talante personal y generacional le sirvieron para develar costumbres virreinales supérstites, hechos y personajes propios de su circunstancia histórica. Argumentativa, porque a través de su discurso literario construyó una narrativa fundamentada en una racionalidad irónica, expresada a través de un humor estético fino: con bromas o burlas que las podemos disfrutar en casi todas sus Tradiciones de carácter social, político y costumbrista. El recurso de la ironía pespunta toda la urdimbre del tejido de los textos tradicionistas, incluso los de sus versos. "La potencia intelectual de un hombre se mide por la dosis de humor que es capaz de utilizar", certera frase de Friedrich Nietzsche que aplica muy bien para don Ricardo.

En una época vacía de argumentos, donde impera el uso y abuso del tuit, es bueno defender y difundir profusamente los breves textos irónicos de Palma para asumir su mensaje y su bella forma de escribir. El tuit vulgar y sarcástico pretende sustituir ahora al género de los aforismos críticos argumentativos. La sociedad peruana (como otras muchas más) está sostenida en una hipérbole de sospecha y vulgaridad que se manifiesta a través de tuits. Casi todo el mundo tuitirrea en el planeta tierra. Es un epifenómeno de la intoxicación informativa, donde abunda la posverdad que viene corrompiendo el lenguaje. Una de sus consecuencias es la propagación de la banalidad de la existencia humana ilustrada con impertinentes selfies, autorretratos al paso.

\section{Hipótesis de trabajo}

¿Es posible una lectura filosófica de las Tradiciones? Estoy seguro que sí. Es lo que intento con el presente ensayo. Creo que con ojos de buen ver podemos descubrir un tipo de racionalidad filosófica, no de carácter lógico, analítico o abstracto sino de 
carácter pragmático, estético y literario, apelado a una crítica irónica del mundo social. Así como el filósofo Pascal dijera, en uno de sus célebres Pensamientos, que burlarse de la filosofía también es hacer Filosofía, a su turno don Ricardo Palma pudo haber dicho que burlarse de la literatura seria es también hacer Literatura.

Con su narrativa tradicionista instauró un estilo de pensar y un estilo de escribir. Una escritura festiva a diferencia de la seriedad melancólica de la literatura romántica (llegada tardíamente a Perú), con la cual se identificó al principio. Palma se refiere a los románticos en "las confidencias amenísimas de La Bohemia de mi Tiempo". Mas, dentro de ese movimiento literario "se insinuaban ya el costumbrista burlón, el ironista agudo", tomando distancia de los románticos; "en ninguno fue tan completo el desengaño ni tan franco, el mea culpa, como en Ricardo Palma”, escribe su hija Angélica Palma (1927:6).

El método de la razón irónica está presente desde los albores de la filosofía griega (con los burlones filósofos cínicos). Pero con la filosofía antropocéntrica de Sócrates -defensor de la tradición oral y de la mayéutica- es que aparece como herramienta teórica: "Conócete a ti mismo", o el "solo sé que nada sé", dos de los principios primeros de la ironía socrática que guiaron sus diálogos con los jóvenes en el ágora pública ateniense.

Desde aquel entonces se instaura un racionalismo irónico en el pensamiento occidental. Esta y otras claves filosóficas, sustentadas por otros filósofos como Aristóteles, quien dice: "la poesía es más filosófica y doctrinal que la historia; por cuanto la primera considera principalmente las cosas en general; pero la segunda las refiere en particular" (1964: 45) y cuando se refiere a la división de la poesía conforme al genio de los poetas, este 
filósofo distinguía entre la poesía que imita acciones nobles y aventuras de sus semejantes (los más graves), dando lugar a la tragedia a través de versos heroicos; y la poesía que imita acciones vulgares (de los ruines), dando lugar a las comedias a través de versos yámbicos y de la ironía que provoca risa o sonrisa (Ibíd.: 33) la comedia es retrato de los peores, porque hay alguna tacha vergonzosa que sea risible; por cuanto lo risible es cierto defecto y mengua sin pesar ni daño ajeno, como a primera ojeada es risible una cosa fea y disforme sin darnos pena (Ibíd.: 34). Muchas de las tradiciones sardónicas e irónicas tienen que ver con ese talante aristotélico, porque buscan suscitar una visión crítica en el lector.

Ricardo Palma fue un fino observador crítico de la moralidad propia de las costumbres (ciudadanas, políticas, religiosas de su época). La primera instancia ética humana se expresa a través de las costumbres (creencias, pautas de comportamiento por imitación familiar y social). Es lo que se llama moral natural. La crítica irónica tradicionista registra esta naturaleza, pero va más allá de ello a través del recurso de la razón irónica buscando que el lector reflexione. Su discurso, en conjunto, es una metafísica de las costumbres.

En ese sentido lo podemos vincular con la propuesta de Manuel Kant, quien en su Crítica de la Razón Práctica habla precisamente de los fundamentos de la metafísica de las costumbres, y del tránsito del conocimiento moral de la razón común al conocimiento filosófico.

En efecto -decía Kant-, si la razón no basta para dirigir seguramente la voluntad en la elección de sus objetos y en la satisfacción de todas nuestras necesidades (que con frecuencia multiplica), si es necesario reconocer que este fin pudiera conseguirse con más seguridad mediante un instinto natural, y si, a pesar de todo, se nos ha dado la razón como 
una facultad práctica, es decir, como una facultad que debe tener influencia sobre la voluntad, es necesario, puesto que se ve por todas partes en las disposiciones de la naturaleza una perfecta conveniencia de los medio a los fines, que su verdadero destino sea el de producir una buena voluntad, no un medio para cualquier fin extraño, sino en sí misma, lo cual exige necesariamente la razón. Podrá, sin duda alguna, no ser esta buena voluntad el único bien, el bien total, pero debe ser considerada como el bien supremo y la condición a que debe subordinarse todo otro bien, todo deseo, aún el de la felicidad. Nada hay aquí que no concuerde perfectamente con la sabiduría de la naturaleza... (1963: 5-7).

Justamente, sobre el relajamiento de las costumbres, Luis Alberto Sánchez acota: el tema de cada tradición no siempre encierra una mera anécdota. Sin quererlo, Palma escoge conflictos de orden personal o colectivo, que comportan un relajamiento de las costumbres de las altas clases o el triunfo del ingenio de los modestos sobre el empaque de los poderosos... La tradición se dirige inesperada e irresistiblemente por los rumbos de una desatada fantasía. De una fantasía crítica, si cabe la aparente paradoja (1973:957-58).

Y así sucesivamente podemos relacionar la narrativa palmista con la de otros filósofos vitalistas, tales como: Federico Nietzsche (quien consideró en su obra Aurora al humor como estrategia: "que el mejor y más efectivo nexo de unión es la risa, el humor y la alegría”; con José Ortega y Gasset, para quien "la metáfora y la ironía representan la forma intelectual efectiva de la razón vital"; logrando Palma alojar el logos originario en el mundo de vida cotidiano, a través de las tradiciones históricas y de la creación literaria.

Para comprender la intencionalidad voluntaria de la obra de Palma, también recurro al actual filósofo alemán Peter 
Sloterdijk, quien distingue entre razón cínica (mala fe) y razón quínica (de burla y resistencia) en su obra Crítica de Razón Cínica. Ya desde el principio de la historia de la filosofía europea se levantó una risa que negaba el respeto al pensamiento serio. Ese impulso quínico se refiere a la integración superadora del filosofar en la vida llena de presencia de espíritu, orientada asimismo a la naturaleza y a la razón. De esta fuente emana el existencialismo crítico de la conciencia satírica. Fácilmente se llega a reemplazar lo malo por lo peor. Hay pocos pasos de la quínina, orientación superadora de la filosofía, a la autonegación cínica de aquello que la filosofía representó en sus mejores aspectos (2003:745-47).

Palma tuvo éxito con su apelación al humor, pues su éxito fue acompañado de la complicidad de sus lectores. Esa fue su estrategia irónica. Esa fue (lo sigue siendo) la ganancia de nosotros sus lectores. Palma sigue vivo. Es contemporáneo nuestro.

No es que Palma se adscribiera a pensamiento filosófico alguno. No. Lo que pasa es que su experiencia y su amplitud cultural le permitieron conceptualizar sobre los acontecimientos de su circunstancia histórica (ambiente de época). "Con la experiencia cuotidiana y larga de los hombres y de las cosas ganó amplitud y altura su filosofía" (Angélica Palma, 1927: 120) ¿Cuál fue su filosofía? La vinculada al raciovitalismo. Para historificar costumbres de su época, dando primacía a la existencia sobre la esencia (existo, luego pienso), es decir, a la vida como "realidad radical" (Ortega y Gasset). Cuando se refiere a su obra Anales de la Inquisición de Lima (publicada en 1863), Palma asume una posición explícitamente filosófica:

Estos Anales -dice- son la armazón de un libro filosóficosocial, que otro más competente escribirá. El autor se conforma con que no se le niegue el mérito de haber 
pacientemente acopiado los datos. La tela y los materiales son suyos. Que otro pinte el cuadro (Ibíd.: 8)

O sea, antes de su primer viaje a Europa, Palma ya tenía prefigurada su visión filosófico-literaria. "En ese viaje cosechó goces su juventud y enseñanzas su espíritu", cuenta su hija Angélica Palma (Ibíd.: 9). En las colecciones de sus versos tituladas Armonías y Pasionarias existen algunas reminiscencias de ese su primer viaje a Europa (España, París, Londres, Venecia), recalca Angélica Palma (Ibíd.: 10)

\section{De la temporalidad de las Tradiciones}

La temporalidad que le interesa es la del Aquí/Ahora. Más no puede ser catalogado solo como un presentista, ni mucho menos como una pasadista que apela a una razón anamnética (propia de la reminiscencia). Claro que ausculta el presente para ir hacia sus raíces, buscando que sus tradiciones calen y se impregnen en la memoria y el imaginario de todos sus vigentes lectores, y de los que están adviniendo. iY vaya que lo logró!, y lo sigue haciendo, porque seguimos leyéndolo. Nos sigue dando qué pensar.

Existe en casi todas sus Tradiciones una fenomenología de lo irónico -en tanto estrategia filosófica y en tanto instrumento metodológico-, que se sitúa en la frontera entre amor/y cinismo burlón; su humor socarrón penetra como cuña en el mundo de las ideas, creencias, achaques y manías de la naciente sociedad republicana peruana. Desarrolla una metafísica de las creencias ("vigencias sociales"), como lo establecido por José Ortega y Gasset: en tanto tránsito de la filosofía moral popular a una metafísica de las costumbres. Es decir, una metafísica de carácter antropológico que muestra la universalidad de lo local (globalización localizada, o localización globalizada). Coincido, en este punto, con lo sustentado por Miguel Ángel 
Vega Centeno en su ponencia "A propósito de las Tradiciones: el localismo global de un clásico" (13 de octubre, 2017).

La potencia evocadora (del pasado), y el personal humorismo para expresarla, son dos características fundamentales de su obra. Pero Palma como hombre ilustrado que fue se movió entre el mundo de las ideas y el de las creencias, entre lo sabido y lo consabido, para decirlo con terminología propia de Ortega y Gasset; donde lo sabido (mundo de ideas) se relaciona tensamente con lo consabido (mundo de creencias y costumbres).

La razón cínica cumple una bifronte función: por un lado es una forma de resistencia y crítica a lo establecido mediante la burla y la risa (razón quínica); y, por otro lado, se instala en el mundo ilustrado bajo un ejercicio sistémico de mala fe, de mentira y de simulacro cínico (posverdad, se denomina hoy en día), corrompiendo las costumbres. La crítica de la razón quínica (irónica) es integradora "porque no se deja seducir por la atracción de los "grandes problemas", sino que encuentra sus temas fundamentalmente abajo del todo: en la cotidianidad, en lo que se considera sin importancia, en todo aquello de lo que, por lo demás, no merece la pena hablar, en las pequeñeces", escribe Peter Sloterdijk (2003: 227). La voluntad y obra irónica de Palma cumplió - a través de la escritura tradicionista- una función integradora

Palma no fue tradicionalista (empozado en el pasado). Fue un tradicionista: rescatador de tradiciones del mundo de vida que resistió a ser colonizado por el mundo sistémico (propio de la administración del poder), por lo que se mantiene vigente, gracias a su genio creativo.

La temporalidad de sus Tradiciones es transhistórica, donde lo histórico (como realidad histórica espacio-temporal) está 
insertado en un peculiar contínuum de "acción": pasado, presente y futuro, como cuando se piensa que también lo presente y hasta lo futuro forma y formará parte de la historia de la Humanidad. Ese contínuum no abarca solo la humanidad, sino también la Naturaleza en cuanto "morada" de la Humanidad y "objeto" de su acción. Y siguiendo a Heidegger, podemos decir que las Tradiciones Peruanas historifican lo trasmitido o tradicional en cuanto tal, sentido de "histórico" entrañado en la consideración de que lo no trasmitido del pasado a tiempos ulteriores desaparece de la historia.

Lo inserto en el contínuum mencionado, este continuo y lo tradicional, se comprenden "inmediata y regularmente" también "ante los ojos", ante nuestra mirada. Los textos de Palma están vigentes, ante nuestros ojos para nuestro goce estético. Están al servicio nuestra mirada. Palma fue un "mirar-mirante" de su época. Nosotros (y sus lectores futuribles) un "mirar-mirado". Su historicidad [la de sus tradiciones] se temporacía primariamente desde el advenir y no desde el sido, ni menos desde el pasado, como se piensa dentro del ámbito de la historicidad "impropia". (Heidegger, 1971: 418).

Palma no creyó que todo tiempo pasado fuese mejor, pero tampoco necesariamente que todo presente lo sea, aunque sí un futuro imaginado podría ser mejor; además el presente que se hace pasado ya fue, ya no puede ser mejorado ni empeorado, solo está-ahí; en cambio, el futuro adviene inexorablemente hacia Aquí/Ahora desde lo por-ve-nir que intuimos, con novedades. En defensa de su vocación y voluntad creadoras, asentadas en su peruanidad en tanto sentimiento de pertenencia a una incipiente nación republicana, Angélica Palma escribió:

Los vientos de ayer fueron mejores/que los de hoy? No, señores; /el hombre es siempre el mismo; cambia el traje, pero nunca el pelaje". Sin embargo: "el mundo pícaro es 
poético; poco en el hoy, y mucho en el ayer/ iOh! Dejadme vivir con las fantásticas/ o reales memorias de otra edad, / y mamotretos compulsar solícitos/y mezclar la ficción con la verdad (1927: 20)

En ese mismo sentido, cuenta su hija Angélica, que Palma añadió: "Mis libros piedrecillas son históricas/que llevo de la patria ante el altar. / He cumplido un deber. Saberlo bastante. Otros vendrán después: mejor lo harán” (Ibíd.: 36). La idea otros apunta- en este caso- a los otros escritores (sus contemporáneos, y a lo que vendrían en el futuro). La otredad (reconocimiento de los otros, de los demás) es una de las claves existencial de su obraje (en tanto unicidad entre yo/obra): que dio como resultado todo un conjunto de obras creadas gracias a su arduo trabajo de inspiración/transpiración.

Obraje que nos sigue dando que hablar porque nos siguen dando qué pensar. Desde nuestro Aquí/Ahora (el futuro de Ricardo Palma). Y, como bien lo dijera Nietzsche en uno de sus famosos aforismos: "Solamente aquel que construye el futuro tiene derecho a juzgar el pasado".

\section{Bibliografía}

Aristóteles (1964). El Arte Poética. Madrid: Editorial Espasa Calpe, tercera edición.

Arista Montoya, L. A. (1993). José Ortega y Gasset, Pensador de la Crisis. Lima: Orellana Editor.

Heidegger, M. (1971). El Ser y el Tiempo. México: Fondo de Cultura Económica.

Kant, M. (1963). Crítica de la Razón Práctica. México: Editora Nacional. 
Palma, R. (2011). Tradiciones Peruanas. 12 tomos Lima: Universidad Ricardo Palma y La República. División Editorial del Diario La República

Palma, A. (1927). Ricardo Palma. El Tradicionista. Lima: Editorial Castillón Silva.

Sánchez, L. A. (1973). Literatura Peruana. Derrotero para una historia cultural del Perú. Lima: Villanueva Editor.

Sloterdijk, P. (2003). Critica de la Razón Cínica. España: Ediciones Siruela. Traducción: Miguel Ángel Vega Cernuda.

Vega Centeno, M. A. (2017). A propósito de las Tradiciones: el localismo global de un clásico. Ponencia sustentada en el Instituto Ricardo Palma. Lima: Universidad Ricardo Palma.

Recibido el 12 de diciembre del 2017 Aprobado el 29 de enero del 2018 